\title{
TEMPERATURE DEPENDENT DEVELOPMENT RATES OF PARASITOID, HABROBRACON HEBETOR, DIRECTLY FED ON BACILLUS THURINGIENSIS VAR. KURSTAKI
}

\author{
Deepak Singh ${ }^{1}$, Isaac L. Mathew ${ }^{1 *}$ and Shilpi Smita Singh ${ }^{2}$ \\ ${ }^{1}$ Department of Zoology, St Andrew's College, Gorakhpur- 273 001, Uttar Pradesh, India \\ isaaclmathew@gmail.com \\ ${ }^{2}$ Department of Zoology, RML Awadh University, Ayodhya- 224 001, Uttar Pradesh, India
}

\begin{abstract}
The interaction of temperature and directly ingested Bacillus thuringiensis (Bt), on the developmental rates of the parasitoid Habrobracon hebetor progeny was investigated using Corcyra cephalonica $4^{\text {th }}$ instar larvae as host. Development rates increased with temperature rise. Regression analysis revealed highly significant $(\mathrm{p}$ $<.01)$ good fit of the equation for incubation, larval and total lifecycle period, while significant $(\mathrm{p}<.05)$ for larval period in untreated diet fed $H$. hebetor, However, under the influence of $B t$ - honey diet, larval period $(\mathrm{p}>.05)$ was not a good fit of the equation. Although r- values were overall lower and regression showed no significant fit of the equation for larval periods, significantly higher development rate was observed towards higher temperatures. However, rates during pupal period and total lifecycle showed highly significant $(\mathrm{p}<.01)$ good fit of the equation. Significant interactions between $B t$ and temperature were observed during larval $\left(\mathrm{F}_{3,72}=45.443, \mathrm{p}<.001\right)$ and pupal periods $\left(\mathrm{F}_{3,72}=3.932, \mathrm{p}<.05\right)$, however, no such significant interaction occurred during incubation period $\left(\mathrm{F}_{3,72}=1.643, \mathrm{p}=\right.$ .187). Mean developmental rates during total life cycle also showed significant interaction between the factors, $\mathrm{F}_{3,72}=4.684, \mathrm{p}<.01$. Temperature was way more influential in all stages, as a factor $(\mathrm{p}<.001)$, than $B t$. This study emphasizes the importance of temperature as an ecofactor during combined biological control. Interaction between higher temperatures and $B t$, within the tolerance limit, may actually be beneficial through faster development during larval stage; although the same cannot be said of the other parameters of its life history.
\end{abstract}

KEYWORDS : Bacillus thuringiensis, Habrobracon hebetor, Parasitoids, temperature, biocontrol.

\section{INTRODUCTION}

Temperature sets the limits of biological activity in arthropods and regulates population dynamics and seasonal occurrence of insect pests and their parasitoids ${ }^{7}$. Both parasitoids and predators are helpful in regulation of pest population because they are lethal and tend to be density-dependent mortality factor ${ }^{3}$. They are more frequently used than predators in pest suppression programmes ${ }^{3}$. Habrobracon hebetor $\mathrm{Say}^{20}$, (Hymenoptera: Braconidae) attacks many Lepidopteran larvae destructive to stored grain products, mainly moths in the family Pyralidae. It works as a potential biocontrol agent against stored grain Lepidopteran pests, like Corcyra cephalonica Stainton ${ }^{23}$, (Lepidoptera: Pyralidae) and many others $^{14,17}$. C. cephalonica is a primary pest of all cereals, particularly rice, but is also capable of damaging all kind of food grains causing tremendous economic impact ${ }^{16}$.

Integration of two or more biocontrol agents are being intensely considered and promoted to complement the effects of each other because of their environmental safety and pest selectivity. The suitability of 
combining microbial biopesticide, Bacillus thuringiensis (Bt), and other biological control agents, such as an insect parasitoid, for pest management of stored cereals have been evaluated to a large extent ${ }^{12,15}$. Interactions between parasitoids and their hosts are strongly influenced by changing in the temperature. It affects the parasitoid in several ways directly or indirectly by reducing survival, retarding development or suppressing its reproduction ${ }^{4,5,13}$ and likely to influence the successful use of parasitoids. Although the effect of temperature $^{6,10,21}$ and several other factors on parasitoids have been studied, the influence of direct $B t$ ingestion, and the interaction involving temperature on the developmental rates of the parasitoid $H$. hebetor is being investigated.

\section{MATERIALS AND METHODS}

Insects cultures were maintained (Singh, 2004) from insects obtained from Central Integrated Pest Management Centre (CIPMC), Gorakhpur, Uttar Pradesh, India. Rearing of the pest and parasitoid was done according to $\operatorname{Singh}^{22}$ et al., 2014, and Mathew ${ }^{11}$ et al., 2018. The $B t$ used, was the commercial formulation Dipel DF ( $B$. thuringiensis var. kurstaki, strain ABTS-351, $32 \mathrm{MIU} \mathrm{g}^{-1}$ [millions of International Units per gram]) from Valent Biosciences Corporation, USA.

Mixed untreated grain diet of equal proportions of Wheat, Maize, Rice, and Sorghum was used in rearing as well as control experiments. Whereas, for study of direct effect of $B t$, similar number of larvae were exposed to a gravid parasitoid female fed on $10 \%$ honey solution containing $B t$ at the rate of $500 \mathrm{ig} / \mathrm{ml}$ for 24 hours ${ }^{9,12}$. They were covered with a muslin cloth, kept at constant temperatures of 20,25, 30 and $35^{\circ} \mathrm{C}, 70 \pm 10 \%$ relative humidity and $12: 12$ L:D photoperiod in 10 replicates each. Each replicate was exposed to a gravid female parasitoid for $24 \mathrm{hrs}$. The beakers were observed after the period for any larval mortality/ parasitization; afterward, the parasitized host larvae were incubated and carefully monitored daily for various life stages $^{15}$.

\section{Statistical Analysis}

Data from $B t$ treatments on different development parameters were subjected to analysis of variance (One Way and Two Way ANOVA) and mean separation tests were conducted with Tukey's B test using SPSS Statistics version 20.0 (SPSS Inc., Chicago, IL, USA) Statistical Analysis Software. Pearson correlations were also carried out between developmental parameters of $H$. hebetor and temperature.

\section{RESULTS AND DISCUSSION}

Temperature rise, in general, caused increase in the development rates of all stages. Regression between increasing temperature and the developmental rates of various life stages of the life history of untreated honey fed $H$. hebetor, highly significant $(\mathrm{p}<.01)$ good fit of the equation for incubation, larval and total lifecycle period, while significant $(\mathrm{p}<.05)$ for larval 
period (Table 1). The extent of correlation was very high $(r=.999)$ between temperature and average developmental rate during total life cycle, showing a very linear relationship. However, under the influence of Bt- honey diet, larval period ( $\mathrm{p}>.05)$ was not a good fit of the equation. $\mathrm{R}$ values were overall lower and regression showed no significant fit of the equation for larval periods, however, pupal period and total lifecycle showed highly significant $(\mathrm{p}<.01)$ good fit of the equation. Although, correlation of larval development rates to temperature was not significant, as compared to the control; significantly higher development rate was observed towards higher temperatures. Two-way ANOVA to examine the effect of $B t$ treatment and temperature on developmental rates showed statistically significant interaction during larval $\left(\mathrm{F}_{3,72}=45.443, \mathrm{p}<.001\right)$ and pupal periods $\left(\mathrm{F}_{3,72}=3.932, \mathrm{p}<.05\right)$, and no significant interaction during incubation period $\left(\mathrm{F}_{3,72}=1.643, \mathrm{p}=.187\right)$. Similarly, total life cycle also showed significant interaction between factors, $\mathrm{F}_{3,72}=4.684, \mathrm{p}$ $<.01$. At all stages, temperature was way more influential, as a factor $(\mathrm{p}<.001)$, than the $B t$ treatments.

Table 1. Mean developmental rates of various particulars of life history of Habrobracon hebetor at various constant temperatures, and the effect of direct Bt ingestion

\begin{tabular}{|c|c|c|c|c|c|c|}
\hline \multicolumn{7}{|c|}{ Parasitoids directly fed untreated $10 \%$ Honey diet } \\
\hline \multirow[t]{2}{*}{ Variables } & Temperature & & & & \multirow{2}{*}{$\begin{array}{l}\text { Regression } \\
\text { equation }\end{array}$} & \multirow[t]{2}{*}{ r-value } \\
\hline & $20^{\circ} \mathrm{C}$ & $25^{\circ} \mathrm{C}$ & $30^{\circ} \mathrm{C}$ & $35^{\circ} \mathrm{C}$ & & \\
\hline Incubation Period & $0.25 \pm 0.00 \mathrm{Aa}$ & $0.45 \pm 0.00 \mathrm{Ab}$ & $0.70 \pm 0.00 \mathrm{Ac}$ & $0.80 \pm 0.02 \mathrm{Ad}$ & $Y=-0.50+0.04 X$ & $.987 * *$ \\
\hline Larval period & $0.32 \pm 0.01 \mathrm{Aa}$ & $0.40 \pm 0.00 \mathrm{Ab}$ & $0.55 \pm 0.01 \mathrm{Ac}$ & $0.57 \pm 0.01 \mathrm{Ac}$ & $Y=-0.04+0.02 \mathrm{X}$ & $.969^{*}$ \\
\hline Pupal period & $0.08 \pm 0.01 \mathrm{Aa}$ & $0.12 \pm 0.02 \mathrm{Ab}$ & $0.17 \pm 0.01 \mathrm{Ac}$ & $0.22 \pm 0.00 \mathrm{Ad}$ & $Y=-0.11+0.01 \mathrm{X}$ & $.997 * *$ \\
\hline Total Life Cycle & $0.05 \pm 0.00 \mathrm{Aa}$ & $0.08 \pm 0.01 \mathrm{Ab}$ & $0.11 \pm 0.00 \mathrm{Ac}$ & $0.13 \pm 0.01 \mathrm{Ad}$ & $Y=-0.06+0.01 \mathrm{X}$ & $.999 * *$ \\
\hline \multicolumn{7}{|c|}{ Parasitoids directly fed 500ug/mL Bt-10\% Honey diet } \\
\hline Incubation Period & $0.25 \pm 0.01 \mathrm{Aa}$ & $0.44 \pm 0.01 \mathrm{Ab}$ & $0.72 \pm 0.02 \mathrm{Ac}$ & $0.77 \pm 0.01 \mathrm{Ad}$ & $Y=-0.46+0.04 X$ & $.974 *$ \\
\hline Larval period & $0.25 \pm 0.01 \mathrm{Ba}$ & $0.32 \pm 0.01 \mathrm{Bab}$ & $0.43 \pm 0.01 \mathrm{Bb}$ & $1.03 \pm 0.07 \mathrm{Bc}$ & $Y=-0.84+0.05 X$ & .884 \\
\hline Pupal period & $0.09 \pm 0.00 \mathrm{Ba}$ & $0.11 \pm 0.00 \mathrm{Bb}$ & $0.18 \pm 0.01 \mathrm{Bc}$ & $0.21 \pm 0.01 \mathrm{Ad}$ & $Y=-0.08+0.01 \mathrm{X}$ & $.983^{* *}$ \\
\hline Total Life Cycle & $0.05 \pm 0.00 \mathrm{Aa}$ & $0.07 \pm 0.00 \mathrm{Bb}$ & $0.10 \pm 0.00 \mathrm{Ac}$ & $0.14 \pm 0.00 \mathrm{Ad}$ & $Y=-0.08+0.01 X$ & $.992 * *$ \\
\hline
\end{tabular}

Means and Standard error followed by different lower case letters in the same row, and uppercase letters in the same column between same variable, are significantly different $(\mathrm{P}<0.05)$ using Tukey's B test.

* Correlation is significant at the 0.05 level

**Correlation is significant at the 0.01 level 
Females $H$. hebetor, being synovigenic, have very limited number of mature eggs when they emerge, and for production of further eggs depend on adult nutrition and host-feeding ${ }^{8}$. Therefore, any toxin present in the food may get absorbed by the gut and can easily get incorporated into the developing egg. This can, in fact, affect the developmental and life history parameters of the parasitoid progeny ${ }^{12}$. Studies have shown that, $B t$ infection of host larvae increases the content of some amino acids, proteins $^{12,19}$ and cause double fold increase in lipid concentration. This may lead to a haemolymph more nutritious than otherwise. The observation that, larval development rates are significantly accelerated when female parent is directly fed $B t$, leads to the fact that some portion of $B t$ toxins may act as rich protein source for eggs developing in the parasitoid. Higher development rates indicate a higher quality of host larvae ${ }^{12,18}$ the variations are indicative of nutritive quality of the host larvae compounded by $B t$ and the influences of temperature. Higher temperatures only mobilize more nutrients, so the observations show a good fit of the linear regression equations, as expected, in most respects.

All physiological functions have optimal thermal ranges within which functions are optimal, and negative effects are seen when temperatures depart from this optimal range ${ }^{2}$. In interacting communities, such as parasitoids and their hosts in a grain storage facility, their closely life histories may be closely linked, but may not share the same optimal temperature ranges, development curves, and upper thermal tolerances ${ }^{1}$. As seen in this study, higher temperatures, within the tolerance limit, may actually be beneficial to the development of the parasitoid; although the same cannot be said of the other parameters of its life history. This warrants further future studies in this direction for a holistic approachbased decision. The constant ambient temperatures, at such sites, has to be taken into account when considering an integrated strategy for using $\mathrm{Bt}$ in conjunction with parasitoids.

\section{ACKNOWLEDGEMENTS}

The authors thank Prof. J.K. Lal, Secretary and Principal, St. Andrew's College, Gorakhpur; and DDU Gorakhpur University, Gorakhpur, for providing laboratory and library facilities during the $\mathrm{PhD}$ work, on which this article is based.

\section{REFERENCES}

- $\quad$ Bannerman, J.A. \& B.D. Roitberg, 2014. Impact of extreme and fluctuating temperatures on aphid-parasitoid dynamics. Oikos, 123(1): 89-98.

- Chown, S.L. \& J.S. Terblanche, 2007. Physiological diversity in insects: ecological and evolutionary contexts. In: Simpson, S. J. (ed.), Advances in insect physiology, Vol. 33. Academic Press, pp. 50-152.

- Coppel, H.C. \& J.W. Mertins, 1977. Biological pest suppression (Advanced series in agricultural sciences 4). Springer-Verlag Berlin. Heidelberg, pp. 314.

- Force, D.C. \& P.S Messenger, 1964a. Duration of development, generation time and longevity of three hymenopterous parasites 
of Therioaphis maculate reared at various constant temperatures. Ann. Ent. Soc. Amer., 57: 405-413.

- Force, D.C. \& P.S. Messenger, 1964b. Fecundity, reproduction rates and innate capacity for increase of three parasities of Therioaphis maculata (Buckton). Ecology, 45: 706-715.

- Forouzan, M., M. Amir-Maafi \& A. Sahragard, 2008. Temperature- dependent development of Habrobracon hebetor (Hym.: Braconidae) reared on larvae of Galleria mellonella (Lep.: Pyralidae). J. Entomol. Soc. Iran., 28: 6778.

- Golizadeh, A., M. Alikhani, M. Hassanpour, A. Enkegaard, H. Rafiee-Dastjerdi \& J. Razmjou, 2017. Comparative biology and life table of Habrobracon hebetor (Hymenoptera: Braconidae) on Anagasta kuehniella (Lepidoptera: Pyralidae) at five constant temperatures. International Journal of Pest Management, 63(4): 364-370.

- Gündüz, E.A. \& A. Gülel, 2010. Protein, lipid and glycogen levels in the parasitoid Bracon hebetor Say (Hymenoptera: Braconidae). Turkish Journal of Zoology, 34: 243-248.

- Hafez, M., H.S. Salama, R. Aboul-Ela, F.N. Zaki \& M. Ragaei, 1995. Effect of Bacillus thuringiensis on Apanteles ruficrus parasitizing the larvae of Agrotis ypsilon. Journal of Islamic Academy of Sciences, 8(1): 33-36.

- Kim, N., J. Na \& M. Ryoo, 2000. Effect of temperature on the development of Bracon hebetor (Hymenoptera: Braconidae) parasitizing Indian meal moth (Lepidoptera: Pyralidae). Korean Journal of Applied Entomology, 39(4): 275-279.

- $\quad$ Mathew, I.L., D. Singh \& C.P.M. Tripathi, 2018. Effect of Bacillus thuringiensis Berliner var. Kurstaki on the life history of Habrobracon hebetor Say (Hymenoptera: Braconidae), Research Journal of Life Sciences, Bioinformatics, Pharmaceutical and Chemical Sciences, 4(3): 478-494.

- Mathew, I.L., 2019. Effect of Bacillus thuringiensis on Habrobracon hebetor Say. (Hymenoptera: Braconidae) during combined biological control of Corcyra cephalonica (Stainton) (Lepidoptera: Pyralidae). [PhD thesis]. Deen Dayal Upadhyay Gorakhpur University, Gorakhpur, Uttar Pradesh, India.

- Messenger, P.S., 1970. Bioclimatic inputs to biological control and pest management programmes. In: R.L. Rabb, and F.E. Gutherie, (eds), Concepts of pest management, North Carolina State Univ. Raleigh, pp. 88-94.

- Nikam, P.K. \& C.V. Pawar, 1993. Life tables and intrinsic rate of natural increase of Bracon hebetor Say. (Hymenoptera: Braconidae) population on Corcyra cephalonica Staint. (Lepidoptera: Pyralidae), a key parasitoid of Helicoverpa armigera Hbn. (Lep., Noctuidae). J. Appl. Entomol., 115: 210-213.

- $\quad$ Oluwafemi, A.R., Q. Rao, X.Q. Wang \& H.Y. Zhang, 2009. Effect of Bacillus thuringiensis on Habrobracon hebetor during combined biological control of Plodia interpunctella. Insect Science, 16(5): 409-416.

- Piltz H., 1977. Corcyra cephalonica (Staint.). In: J. Kranz, H.Schmutterer and W. Koch (eds), Disease pests and weeds tropical crops (Berlin and Hamburg: Verlag Paul Parey), pp. 439-440.

- Radhika, P. \& K.C. Chitra, 1998. Correlation between life expectancy and adult emergence in Bracon hebetor as influenced by larval nutrition. Indian Journal of Plant Protection, 26(1): 68-71.

- Romeis, J., M. Meissle \& F. Bigler, 2006. Transgenic crops expressing Bacillus thuringiensis toxins and biological control. Nature biotechnology, 24(1): 63-71.

- $\quad$ Salama, H. S., A. Sharaby \& M. Ragaei, 1983. Chemical changes in the haemolymph of Spodoptera littoralis [Lep.: Noctuidae] as affected by Bacillus thuringiensis. Entomophaga, 28(4): 331-337.

- Say T., 1836. Descriptions of new North 
American Hymenoptera, and observations on some already described. Boston Journal of Natural History, 1(3): 210-305.

- Shojaei, S., M.H. Safaralizadeh \& N. Shayesteh, 2006. Effect of temperature on the functional response of Habrobracon hebetor Say (Hymenoptera: Braconidae) to various densities of the host, Plodia interpunctella Hubner (Lepidoptera: Pyralidae). Pak. Entomol., 28(1): 51-55.
- $\quad$ Singh, D., R.P. Singh \& C.P.M. Tripathi, 2014. Effect of temperature on life table statistics of Bracon hebetor (Say) (Hymenoptera: Braconidae). International Journal of Innovation and Applied Studies, 7: 497-500.

- Stainton, H.T., 1866. Description of a new species of family "Galleriidae". Entomological monthly Magazine, 2: 172173. 
